\title{
Step Count Accuracy of Several Commercial Activity Trackers While Riding a Motorcycle
}

Rieck, Thomas M.1, Rieck, Katie M., M.D.

\section{BACKGROUND} - Sedentary time, especially prolonged sitting time, has been
shown to have negative consequences on an individual's health, even if they regularly exercise [1].

- In order to combat excessive sedentary time, as well as recording the amount of movement one achieves trackers to help achieve better overall health [2].

Use of activity trackers has exploded in popularity in the

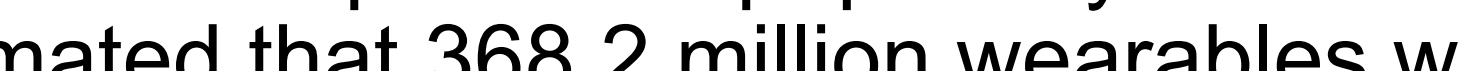

Use of an activity tracker has been shown to increase abandonment or these devices is high $[4,5]$.

Health and fitness professionals are often asked "Which device should I purchase?" and "How accurate are the devices?"4 It has been noted that if a device is perceived as more accurate, it has a higher adoption and usage rate

- Though many devices have been studied across a variety of conditions[8], no study to date has looked at the
accuracy of these devices while riding a motorcycle.

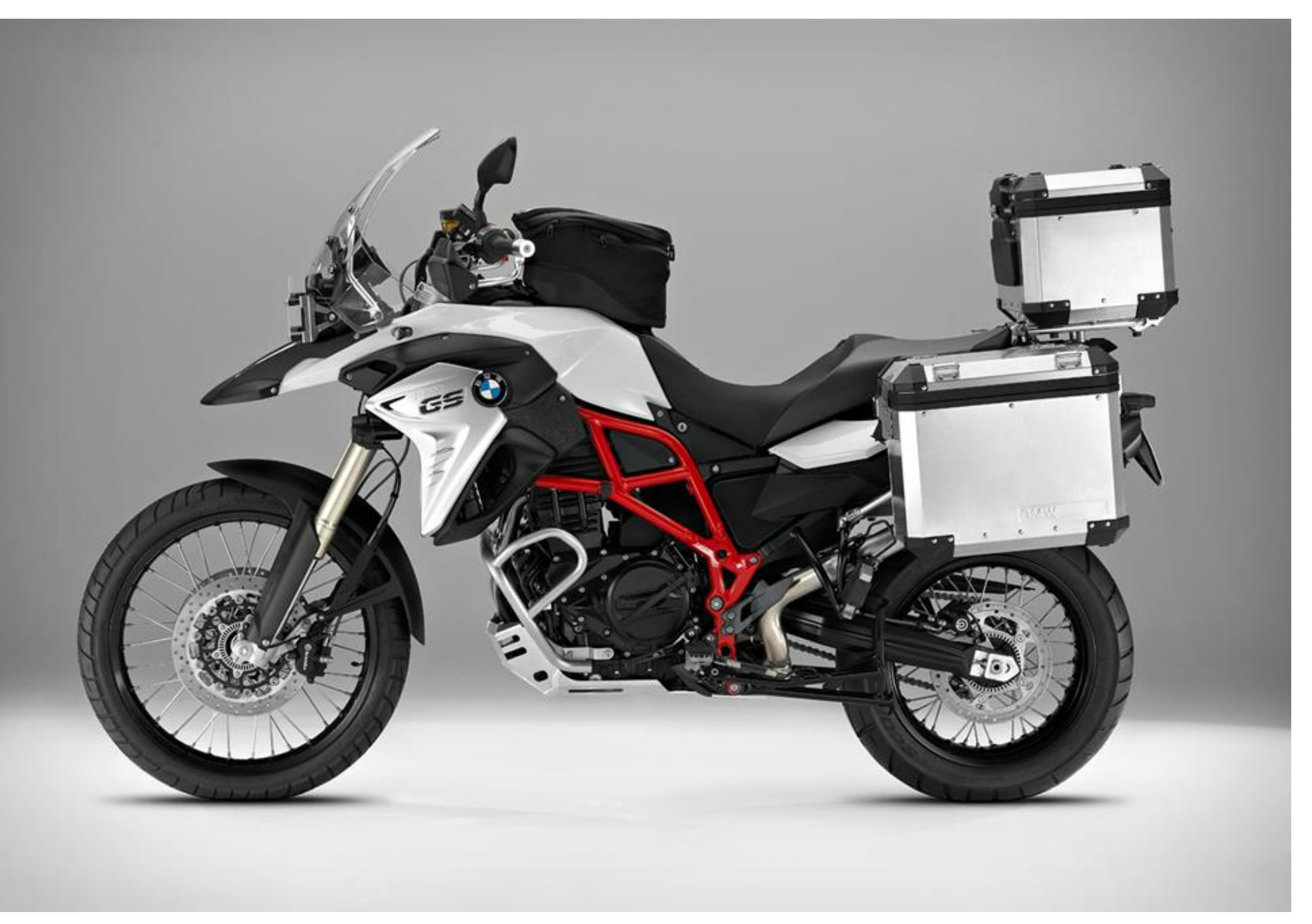

\section{STUDY AIM}

To determine whether several commercially-available activity To determine whether several commercially-available activity
trackers will misclassify movement from riding a motorcycle as step activity

\section{DEVICES}
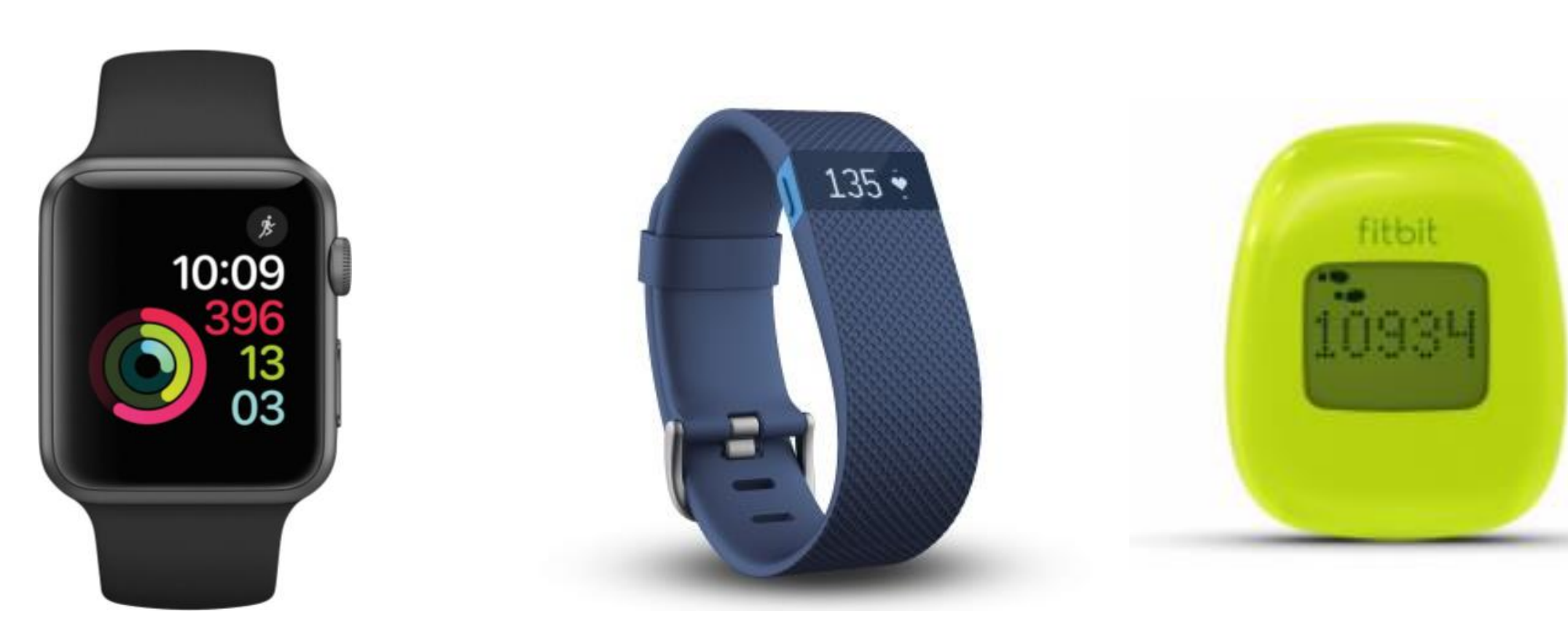

Apple Watch

Fitbit Charge HR

Fitbit Zip

\section{METHODS}

PROCEDURE:

- For all trials, the motorcyclist wore the Apple Watch ${ }$ (Generation 1) on their dominant hand, the Fitbit Charge $H R \otimes$ was worn on their nondominant hand, and the Fitbit Zip® was placed in their left pocket.

- Height and weight, along with sex, birth date, and dominant phone application.

- Before riding the approximate 28 mile route, the motorcyclist sat astride the motorcycle, with both feet on

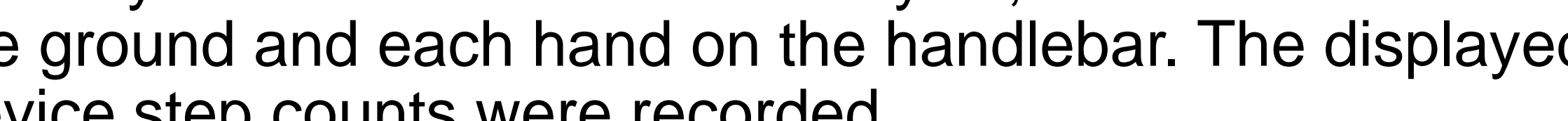

The motorcyclist then rode the route, riding within the prescribed traffic control and speed limits, until reaching the

- At the midpoint, and without removing his hands from the handlebars or dismounting the motorcycle, the displayed

step counts were recorded.

- The motorcyclist then rode back to the starting point, again not moving from the riding
counts were recorded.

- Ten total round-trip trials were complete. DATA ANALYSIS:

- The difference between the number of steps measured by the device and the actual number of steps taken

\section{RESULTS}

The mean number of steps miscounted by the Apple Watch was 12.9 steps, while the range varied from 0 to 53 steps. The Apple Watch completed one trial portion without miscounting any steps.

The mean number of steps miscounted by the Fitbit Charge HR was 211.0 steps, while the range varied from 136 to 323 steps.

The mean number of steps miscounted by the Fitbit Zip was 305.3 steps, while the range varied from 20 to 811 steps.

Because the actual step count was equal to zero in all cases, the mean absolute percent error (MAPE) for the Apple Watch, Fitbit Charge HR, and the Fitbit Zip would be $100 \%$.

\begin{tabular}{lccccc}
\multicolumn{5}{c}{ TABLE 1: MEAN STEP DIFFERENCE } \\
\hline All trials & Mean & $\begin{array}{c}\text { Standard } \\
\text { Deviation }\end{array}$ & $\begin{array}{c}P \\
\text { Value }\end{array}$ & Range \\
\hline Apple Watch & 12.9 & 15 & .011 & 0 to 53 \\
\hline $\begin{array}{l}\text { Fitbit Charge } \\
\text { HR }\end{array}$ & 211.0 & 53.1 & $<.01$ & 136 to 323 \\
\hline Fitbit Zip & 305.3 & 309.3 & $<.01$ & 20 to 811 \\
\hline
\end{tabular}

\section{TABLE 2: MEAN STEP DIFFERENCE}

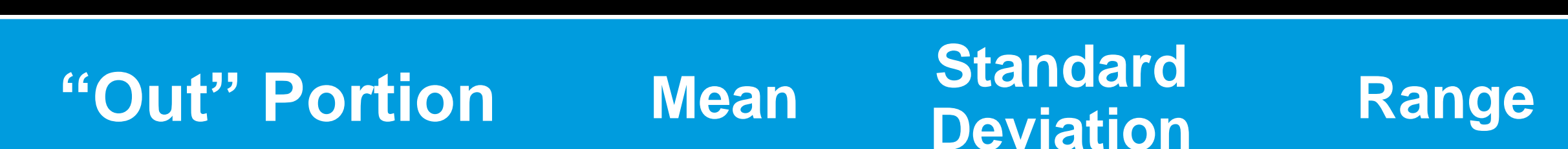
$\begin{array}{llll}\text { Apple Watch } & 19.2 & 20 & 0 \text { to } 53\end{array}$

$\begin{array}{llll}\text { Fitbit Charge HR } & 189.2 & 45.8 & 136 \text { to } 226\end{array}$

$\begin{array}{lrrr}\text { Fitbit Zip } & 149.8 & 121.9 & 20 \text { to } 291\end{array}$

\section{TABLE 3: MEAN STEP DIFFERENCE}

"Back" Portion Mean $\begin{gathered}\text { Standard } \\ \text { Deviation }\end{gathered}$ Range

$\begin{array}{llll}\text { Apple Watch } & 6.6 & 3.4 & 2 \text { to } 11\end{array}$

\begin{tabular}{llll}
\hline Fitbit Charge HR & 232.8 & 55.3 & 180 to 323 \\
\hline
\end{tabular}

$\begin{array}{llll}\text { Fitbit Zip } & 460.8 & 374.1 & 55 \text { to } 811\end{array}$

\section{DISCUSSION}

- This study, the first of its kind known to the authors, investigated the accuracy of several commerciallyavailable activity trackers while riding a motorcycle over a moderate distance.

- Our results noted that each of the studied activity trackers miscounted steps. Only the Apple Watch had one trial where the true step count was exactly matched.

- Because each device has a proprietary algorithm for assessing step counts, we can only speculate as to why each device performed as it did during the motorcycling trials.

Previous research has noted that newer algorithms and additional sensors, such as optical heart rate $[9,10]$. This may be why the Fitbit Zip did poorly compared to the other two activity trackers.

\section{CONCLUSIONS}

In this study, commercially-available activity trackers were shown to misclassify riding a motorcycle as step activity.

Researchers should be cautious when utilizing consumergrade activity tracker step counts in avid motorcyclists.

- For the consumer, the total miscounted steps are relatively small when riding over a moderate distance, and the small metabolic cost of choosing to ride a motorcycle verses drive a vehicle, may overcome these miscounted steps [11,12].

\section{REFERENCES}

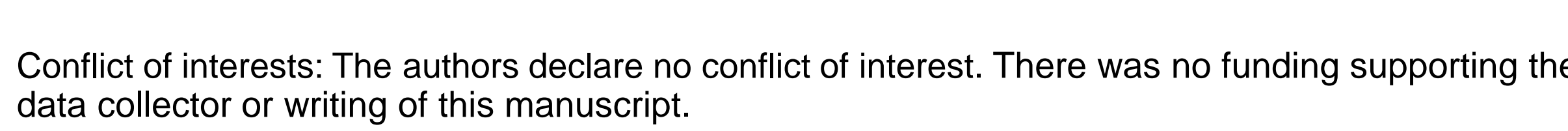

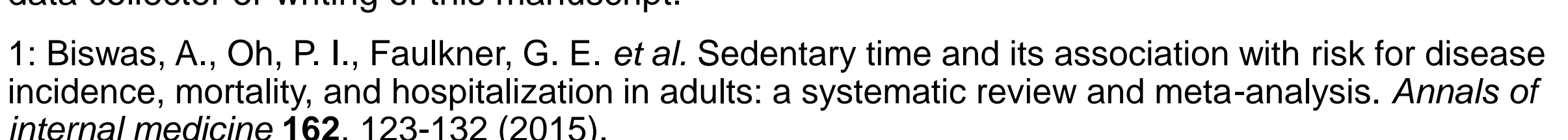
2: Gandhi, M. \& Wang, T. The tuture of biosensing wearables. San Francisco: Fock Health (2014).

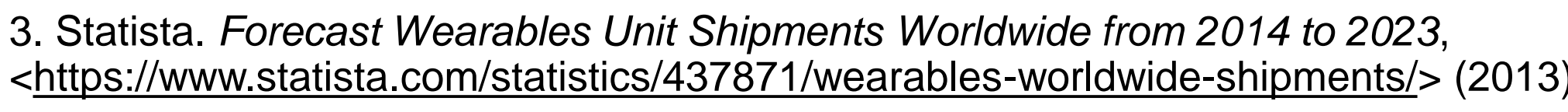

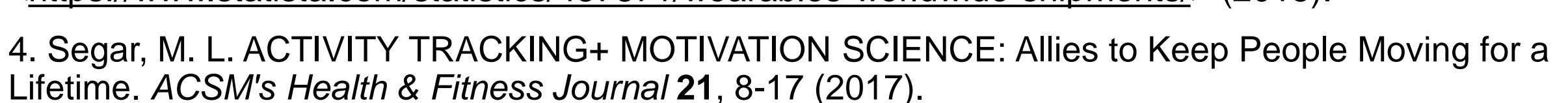

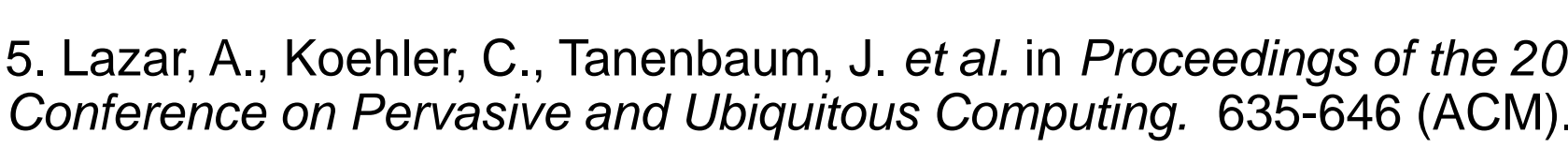

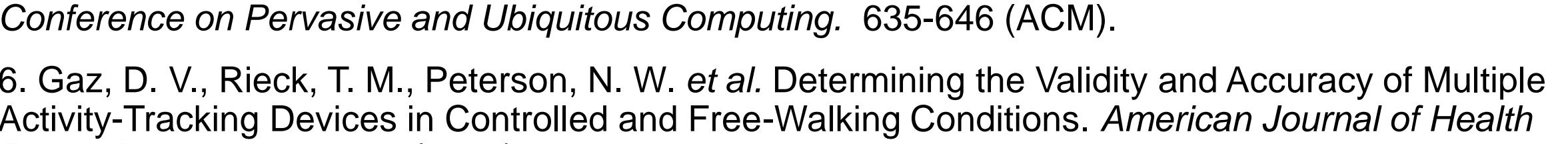

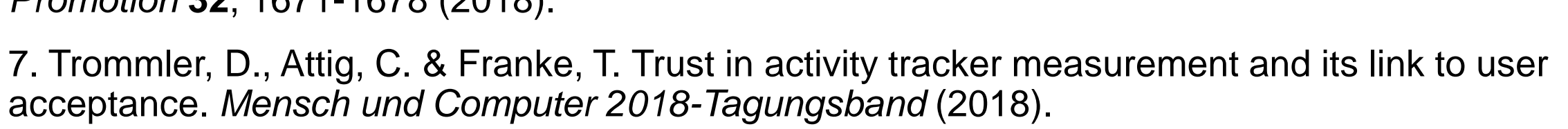

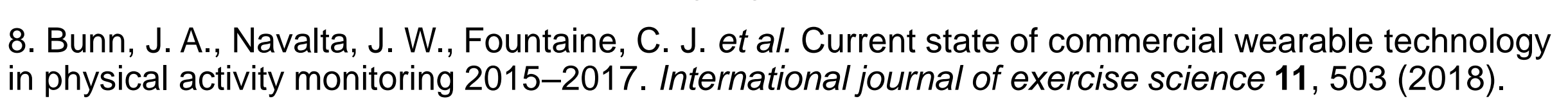

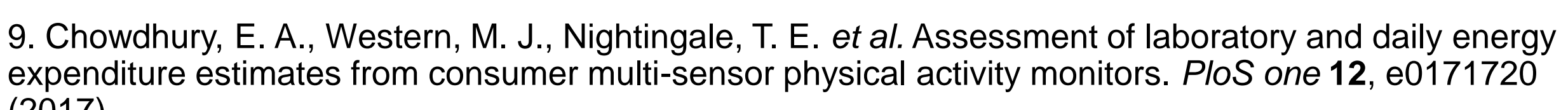

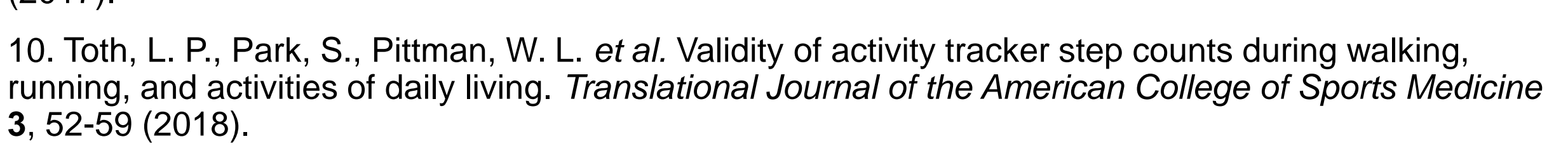

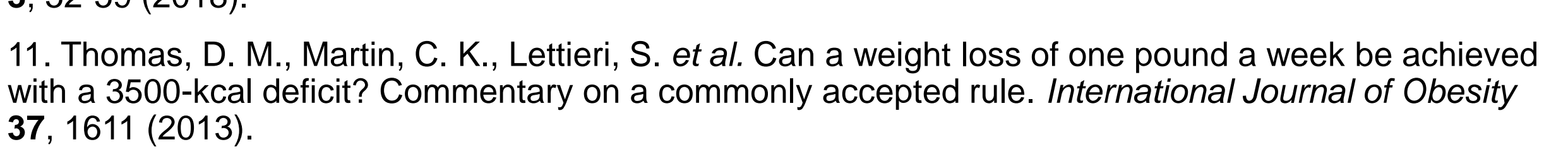

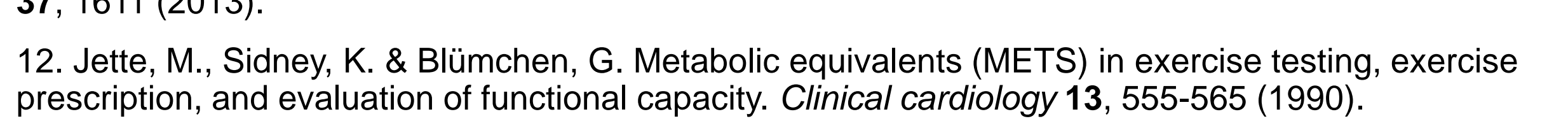

